\title{
A multi-institution phase II study of gemcitabine/S-1 combination chemotherapy for patients with advanced biliary tract cancer.
}

\section{AUTHOR(S):}

Kanai, Masashi; Yoshimura, Kenichi; Tsumura, Takehiko; Asada, Masanori; Suzuki, Chihiro; Niimi, Miyuki; Matsumoto, Shigemi; ... Fukushima, Masanori; Uemoto, Shinji; Hatano, Etsuro

\section{CITATION:}

Kanai, Masashi ... [et al]. A multi-institution phase II study of gemcitabine/S-1 combination chemotherapy for patients with advanced biliary tract cancer.. Cancer chemotherapy and pharmacology 2011, 67(6): 1429-1434

\section{ISSUE DATE:}

2011-06

\section{URL:}

http://hdl.handle.net/2433/143579

\section{RIGHT:}

The final publication is available at www.springerlink.com; This is not the published version. Please cite only the published version.; この論文 は出版社版でありません。引用の際には出版社版をご確認ご利用くだ さい。 


\section{Original Article}

\section{A multi-institution phase II study of gemcitabine/S-1 combination chemotherapy for patients with advanced biliary tract}

\section{cancer}

Masashi Kanai ${ }^{{ }^{*}}$, Kenichi Yoshimura ${ }^{2}$, Takehiko Tsumura $^{3}$, Masanori Asada ${ }^{4}$, Chihiro Suzuki ${ }^{2}$, Miyuki Niimi ${ }^{2}$, Shigemi Matsumoto ${ }^{1}$, Takafumi Nishimura ${ }^{1}$ Takashi Nitta $^{5}$, Kentaro Yasuchika ${ }^{5}$, Kojiro Taura ${ }^{5}$, Yukiko Mori ${ }^{1}$, Akihiko Hamada ${ }^{6}$, Naoya Inoue ${ }^{7}$, Shinsuke Tada ${ }^{8}$, Kazuhiro Yanagihara ${ }^{1}$, Shujiro Yazumi ${ }^{4}$, Yukio Osaki ${ }^{3}$, Tsutomu Chiba ${ }^{1,8}$, Iwao Ikai ${ }^{5}$, Masanori Fukushima ${ }^{2}$, Shinji Uemoto ${ }^{5}$, Etsuro Hatano ${ }^{5}$

1) Outpatient Oncology Unit, Kyoto University Hospital, Kyoto, Japan

2) Translational Research Center, Kyoto University Hospital, Kyoto, Japan

3) Osaka Red Cross Hospital, Osaka, Japan

4) Kitano Hospital, Osaka, Japan

5) Department of Surgery, Graduate School of Medicine, Kyoto University Hospital, Kyoto, Japan

6) Kyoto Katsura Hospital, Kyoto, Japan

7) Kansai Denryoku Hospital, Osaka, Japan

8) Department of Gastroenterology and Hepatology, Kyoto University Hospital, Kyoto, Japan 
Kyoto University Hospital, 54 Shogoin-Kawahara-cho, Sakyo-ku, Kyoto, 606-8507, Japan

*Corresponding author: Kyoto University Hospital, 54 Shogoin-Kawahara-cho, Sakyo-ku, Kyoto, 606-8507, Japan

Tel.: +81-75-751-4770; Fax: +81-75-751-4772

E-mail: kanai@kuhp.kyoto-u.ac.jp 


\section{Abstract}

Purpose: We aimed to evaluate the efficacy and safety of gemcitabine/S-1 combination chemotherapy for the treatment of patients with advanced biliary tract cancer.

Methods: Patients with histologically or cytologically confirmed unresectable or recurrent biliary tract cancer were eligible for inclusion. The primary endpoint was overall survival. Gemcitabine was administered intravenously at a dose of $1,000 \mathrm{mg} / \mathrm{m}^{2}$ over $30 \mathrm{~min}$ on days 1 and 8 and oral S-1 was administered daily at a dose of $60 \mathrm{mg} / \mathrm{m}^{2}$ on days $1-14$. This schedule was repeated every 3 weeks until disease progression or patient refusal.

Results: Twenty-five patients were enrolled between October 2007 and January 2009.

Eleven patients (44\%) had extrahepatic bile duct cancer, $5(20 \%)$ had intrahepatic bile duct cancer, 8 had gallbladder cancer (32\%) and $1(4 \%)$ had ampulla of Vater cancer. The median overall survival time was 12.7 months $(95 \% \mathrm{Cl}, 8.4-23.5$ months) and the 1-year survival rate was $52.0 \%(95 \% \mathrm{Cl}, 31.2-69.2 \%)$. Of the twenty-three patients with evaluable target regions, seven patients experienced a partial response and an overall response rate was $30.4 \%$. The following grade $3-4$ hematological toxicities occurred: neutropenia (56\%), leukopenia (24\%), anemia (8\%) and thrombocytopenia (4\%). In spite of the high incidence of grade 3-4 neutropenia, no patients developed febrile neutropenia in the present study. The 
major grade 3-4 non-hematological toxicities were fatigue (8\%), anorexia (8\%) and diarrhea (4\%).

Conclusions: Gemcitabine/S-1 combination chemotherapy offered a promising survival benefit with acceptable toxicity in patients with advanced biliary tract cancer.

Keywords: Biliary tract cancer - Gemcitabine - S-1 - Chemotherapy 


\section{Introduction}

Biliary tract cancer is one of the most lethal malignancies worldwide, with surgery

representing the only potentially curative treatment for this disease. However, many

patients are diagnosed too late for curative resection, and even if surgery can be performed,

the likelihood of relapse is very high $[7,13]$. Over the past decade, gemcitabine has been

widely used to treat unresectable or recurrent biliary tract cancer $[3,4,9,17,18,23,27]$,

although no phase III trials have established this drug as a standard treatment for advanced

biliary tract cancer. We have previously evaluated the outcome of consecutive 22 patients

with advanced biliary tract cancer who received gemcitabine monotherapy as first line and

reported that median survival time (MST) was 8.3 months (95\% Cl: 6.4-11.2 months) [9].

In the ABC-02 study, the first prospective multicenter phase III study in this field,

gemcitabine/cisplatin combination chemotherapy was compared with gemcitabine

monotherapy. The study found that the combination regimen significantly prolonged MST

(from 8.1 to 11.7 months; $P<0.001$ ) [26]. The superiority of gemcitabine/cisplatin

combination chemotherapy over gemcitabine monotherapy was also demonstrated in a

randomized phase II study conducted in Japan (the BT-22 study) [6]. Given these findings, 
gemcitabine/cisplatin combination chemotherapy is now becoming accepted as a new standard regimen for advanced biliary tract cancer.

S-1 is an oral fluoropyrimidine prodrug that has confirmed efficacy against various solid tumors, both alone and in combination with other cytotoxic drugs $[1,12,14,19,29]$. S-1 monotherapy has yielded good results against advanced biliary tract cancer [5, 24], and gemcitabine/S-1 combination therapy has yielded promising results with acceptable toxicity levels for patients with advanced pancreatic cancer $[15,16,28]$. At the time of planning this clinical trial in 2007 , there had been no reports on gemcitabine/S-1 combination chemotherapy for patients with advanced biliary tract cancer, so we designed this clinical trial to determine its efficacy and safety in this context. 


\section{Patients and methods}

\section{Eligibility criteria}

Patients with advanced biliary tract cancer that was not amenable to potentially curative surgery or that had recurred after surgery were eligible for inclusion if they met the following criteria: histologically or cytologically confirmed biliary tract cancer; Eastern Cooperative Oncology Group performance status of 0-2; age $\geq 20$ years; adequate bone marrow function (neutrophil count $\geq 1,500 / \mathrm{mm}^{3}$, and platelet count $\geq 100,000 / \mathrm{mm}^{3}$ ), liver function (total bilirubin $\leq 3$ times the upper limit of normal (ULN) and aspartate aminotransferase [AST]/alanine aminotransferase $[A L T] \leq 5$ times $U L N$ ), and renal function (creatinine $\leq 1.5 \mathrm{mg} / \mathrm{dL}$ ); adequate oral intake; life expectancy $\geq 3$ months. All patients provided written informed consent.

Exclusion criteria included a history of chemotherapy or radiotherapy (patients who had undergone adjuvant chemotherapy were not excluded if at least 6 months had passed since the last administration), pregnancy or lactation, a history of severe drug allergy, and other severe comorbid diseases. This phase II study (UMIN ID 000000792) was conducted in five institutions in Japan. The protocol was approved by the institutional review board at each institution and patient registration and data management were conducted at an independent data center at Translational Research Center, Kyoto University Hospital. All procedures were performed in accordance with the 1964 Declaration of Helsinki. 


\section{Treatment}

Gemcitabine was infused at a dose of $1000 \mathrm{mg} / \mathrm{m}^{2}$ over $30 \mathrm{~min}$ on days 1 and 8 . S-1 was given orally twice a day for 14 consecutive days. Doses of S-1 were calculated according to body surface area (BSA) as follows: BSA $<1.25 \mathrm{~m}^{2}, 60 \mathrm{mg} /$ day; $1.25 \mathrm{~m}^{2} \leq \mathrm{BSA}<1.5 \mathrm{~m}^{2}, 80$ $\mathrm{mg} /$ day; $B S A \geq 1.5 \mathrm{~m}^{2}, 100 \mathrm{mg} /$ day. The gemcitabine and $\mathrm{S}-1$ treatment regimen was repeated every 3 weeks. Doses were reduced in response to adverse effects (graded according to the Common Terminology criteria for Adverse Events v 3.0) [22].

Chemotherapy was started if on day 1 the neutrophil count was $\geq 1500 / \mathrm{mm}^{3}$, platelet count was $\geq 100,000 / \mathrm{mm}^{3}$, total bilirubin was $\leq 3$ times the ULN, AST/ALT was $\leq 5$ times ULN, and there were no non-hematological toxicities of grade 3 or higher (except for abnormal blood test results not relevant to the chemotherapy regimen). Chemotherapy was continued if on day 8 the neutrophil count was $\geq 1000 / \mathrm{mm}^{3}$, platelet count was $\geq 75,000 / \mathrm{mm}^{3}$, total bilirubin was $\leq 3$ times the ULN, AST/ALT was $\leq 5$ times the ULN, and there were no non-hematological toxicities of grade 3 or higher. If the patient did not meet the above criteria, chemotherapy was delayed by 1 week. If neutropenia (grade 3-4), thrombocytopenia (grade 3-4), febrile neutropenia or non-hematological toxicity associated with gemcitabine (grade 3) occurred, the subsequent gemcitabine dose was reduced to $800 \mathrm{mg} / \mathrm{m}^{2}$. If further toxicity occurred with the reduced dose, it was further reduced to $600 \mathrm{mg} / \mathrm{m}^{2}$. If a further dose 
reduction was necessary, the subsequent gemcitabine dose was reduced by $20 \%$. If diarrhea or stomatitis (grade 3-4) associated with S-1 occurred, S-1 was discontinued and patients were withdrawn from the study. No dose re-escalation was allowed. The treatment regimen was continued until disease progression, unacceptable toxicity including non-hematological toxicity of grade 4 or patient refusal occurred.

\section{Pretreatment and follow up evaluation}

Pretreatment evaluation included obtaining the patient's medical history and performing a physical examination, imaging using contrast-enhanced computed tomography (CT) or magnetic resonance imaging (MRI), a complete blood cell count, serum biochemical tests, an electrocardiogram and chest $\mathrm{X}$-rays. During the treatment cycles, physical examinations and blood tests were scheduled on days 1 and 8. Carcinoembryonic antigen (CEA) and carbohydrate antigen 19-9 (CA19-9) were measured at the time patients were enrolled in the study and every month thereafter. Toxicity was evaluated using the Common Terminology criteria for Adverse Events v3.0 [22].

\section{Statistical analysis}

The primary endpoint was overall survival. The secondary endpoints were toxicity and response rate. Twenty-five patients were enrolled, a sample size that would allow rejection 
of a null hypothesis of a $30 \%$ 1-year survival rate and acceptance of an alternative hypothesis of a $50 \% 1$-year survival rate, with a significance level of 0.05 and a power of $80 \%$. Overall survival was calculated using the Kaplan-Meier method, and was defined as the time from initiation of therapy to death from any cause or the final follow up. Among patients with measurable target lesions, the objective response rate was evaluated according to Response Evaluation Criteria in Solid Tumors (RECIST) version 1.0 [21]. Patients were enrolled between October 2007 and January 2009 and the final analysis was conducted in January 2010 after a 1-year follow-up period. All analyses were conducted on an intention-to-treat basis and were performed using SAS version 9.2 (SAS Institute, Cary, NC, USA). 


\section{Results}

\section{Patient characteristics}

Twenty-five patients were enrolled between October 2007 and January 2009. The patient characteristics are shown in Table 1. The median age was 63 years (range 32-78 years) and 18 patients (72\%) were men. Four of the 25 patients (16\%) experienced recurrent disease after undergoing curative surgery. Out of the 21 patients with unresectable disease, distant metastasis was reported in 13 patients at the time of enrollment. Eleven patients (44\%) had extrahepatic bile duct cancer, 8 had gallbladder cancer (32\%), 5 (20\%) had intrahepatic bile duct cancer and $1(4 \%)$ had ampulla of Vater cancer.

\section{Efficacy}

Seventeen patients (68\%) died during the study period. The median overall survival time was 12.7 months (95\% Cl, 8.4-23.5 months) and the 1-year overall survival rate was $52 \%$ $(95 \% \mathrm{Cl}, 31.2-69.2 \%, p=0.02$ under a null hypothesis of $30 \%)$. Of the 23 patients with target regions that were evaluable according to RECIST, 7 (30.4\%) experienced a partial response and 13 (56.5\%) had stable disease, with an overall disease control rate of $87.0 \%$.

\section{Toxicity}

In total, 229 cycles of gemcitabine/S-1 combination chemotherapy were delivered, with a median of 7 cycles per patient (range 1-20 cycles; Table 1 ). The mean relative dose 
intensities of gemcitabine and S-1 were $75 \%$ and $84 \%$, respectively. The incidence rates of hematological and non-hematological adverse events are summarized in Tables 2 and 3 , respectively. The most common grade 3-4 hematological toxicity was neutropenia (56\%); however, no instances of febrile neutropenia were observed in this study. The incidence rates of grade 3-4 anemia and thrombocytopenia were $8 \%$ and $4 \%$, respectively. Grade 3-4 hyperbilirubinemia and ALT was observed in $16 \%$ and $8 \%$ of patients, respectively, mostly associated with obstructive jaundice caused by the primary disease. Other grade 3-4 non-hematological adverse events were fatigue (8\%), anorexia (8\%) and diarrhea (4\%). 


\section{Discussion}

In our population of patients with advanced biliary tract cancer, gemcitabine/S-1 combination chemotherapy achieved an MST of 12.7 months and a 1 -year survival rate of $52 \%$. The MST for patients with gall bladder cancer $(n=8)$ was shorter $(7.6$ months) than that for patients with other cancer types (16.0 months), which is consistent with the findings of previous studies, and possibly reflects the more aggressive nature of gall bladder cancer $[8,10,20]$. The proportion of patients with gall bladder cancer in our study (32\%) was comparable with the proportions in previous randomized trials $(26-39 \%)[6,25,26]$, so the good MST observed in the current study was unlikely to be simply due to tumor type selection bias. Furthermore, this was a multi-institution trial, and the eligibility criteria were almost identical to indications used for administering chemotherapy in daily clinical practice; both these factors are likely to have contributed to reducing selection bias. Although comparing single-arm phase II studies can be problematic, our current results are comparable to those of Sasaki et al., who observed an MST of 11.6 months and a 1-year survival rate of $44 \%$ among patients with advanced biliary tract cancer treated with gemcitabine/S-1 combination chemotherapy [20](Table 4). Their treatment schedule differed slightly from ours: it consisted of $1000 \mathrm{mg} / \mathrm{m}^{2}$ gemcitabine on days 1 and 15 , and $80 \mathrm{mg} / \mathrm{m}^{2} \mathrm{~S}-1$ daily for 14 consecutive days every 4 weeks. In this study, grade 3-4 neutropenia was observed in $56 \%$ 
of patients and this often caused suspension of chemotherapy on day 8 . In fact, planned chemotherapy administration on day 8 needed to be suspended in $28.5 \%$ of cycles.

Meanwhile, Sasaki et al. reported grade 3-4 neutropenia was 34\% and their regimen might have an advantage of avoiding suspension of chemotherapy due to neutropenia because gemcitabine administration was scheduled on day 1 and 15, not on day 8 with 2 week interval. Interestingly, a previous study of gemcitabine/cisplatin combination therapy in Japanese patients (BT-22 study) yielded a 56.1\% incidence rate of grade 3-4 neutropenia, whereas in ABC-02 study involving the same regimen, the rate was only $22.6 \%$ among Caucasian patients $[6,26]$. Although we need to take into account the difference of treatment duration between 2 studies (up to 24 weeks in ABC-02 study versus up to 48 weeks in BT-22 study), it is tempting to speculate that ethnic differences exist between patients with biliary tract cancer in terms of susceptibility to gemcitabine-related neutropenia. In spite of the high incidence of grade 3-4 neutropenia in the present study, no patients developed febrile neutropenia, probably due to the short duration of neutropenia caused by this combination therapy. Aside from AST/ALT elevation, the most common non-hematological toxicity was fatigue (52\%); however, the incidence rates of grade 3-4 toxicities were relatively low, showing that this regimen was generally well tolerated in an outpatient setting. The grade 3-4 hyperbilirubinemia observed in this study was associated with obstructive jaundice caused 
by the primary disease, and so was unlikely to be relevant to the combination therapy

regimen. In vitro study also demonstrated the advantage of gemcitabine/S-1 combination.

Yoshizawa et al. tested the combination of S-1 with other anti-cancer drugs (gemcitabine,

cisplatin, irinotecan, mitomycin C, adriamycin, and paclitaxel) and reported that synergic

effect was most evident in gemcitabine/S-1 combination [30]. The combination of

gemcitabine and another oral fluoropyrimidine, capecitabine, was found to be similarly

efficacious in previous single-arm phase II studies $[2,10,11]$. In their respective studies,

Cho et al. observed an MST of 14 months and a 1-year survival rate of 58\% [2], and Knox et al. also observed an MST of 14 months and a 1-year survival rate of $49 \%$ [10]. Koeberle et al. found similar results, with an MST of 13.2 months [11](Table 4). Koeberle et al. also highlighted the importance of maintaining a balance between treatment efficacy and quality of life in palliative chemotherapy for advanced biliary tract cancer. From the point of view of quality of life, combination therapy using oral fluoropyrimidines has the major advantage of being very convenient to administer. Clearly, we must be cautious about the interpretation of data from single-arm phase II studies; however, the combination of gemcitabine and oral fluoropyrimidines can be used for patients with advanced biliary tract cancer in situations that preclude the use of cisplatin (e.g. allergy to cisplatin or intolerance to fluid infusion before/after cisplatin administration). In summary, gemcitabine/S-1 combination 
chemotherapy yielded a promising survival benefit with acceptable toxicity in patients with advanced biliary tract cancer. We believe that this regimen would be a good candidate for the experimental arm of a future phase III trial of gemcitabine/cisplatin combination therapy.

\section{Acknowledgements}

This work was supported by the Smoking Research Foundation. We thank Hiroe Tada for her valuable support. 


\section{References}

[1] Boku N, Yamamoto S, Fukuda H, Shirao K, Doi T, Sawaki A, Koizumi W, Saito H, Yamaguchi K, Takiuchi H, Nasu J, Ohtsu A (2009) Fluorouracil versus combination of irinotecan plus cisplatin versus S-1 in metastatic gastric cancer: a randomised phase 3 study. Lancet Oncol 10: 1063-9

[2] Cho JY, Paik YH, Chang YS, Lee SJ, Lee DK, Song SY, Chung JB, Park MS, Yu JS, Yoon DS (2005) Capecitabine combined with gemcitabine (CapGem) as first-line treatment in patients with advanced/metastatic biliary tract carcinoma. Cancer 104: 2753-8

[3] Eckel F, Schmid RM (2007) Chemotherapy in advanced biliary tract carcinoma: a pooled analysis of clinical trials. Br J Cancer 96: 896-902

[4] Eng C, Ramanathan RK, Wong MK, Remick SC, Dai L, Wade-Oliver KT, Mani S, Kindler HL (2004) A Phase II trial of fixed dose rate gemcitabine in patients with advanced biliary tree carcinoma. Am J Clin Oncol 27: 565-9

[5] Furuse J, Okusaka T, Boku N, Ohkawa S, Sawaki A, Masumoto T, Funakoshi A (2008) S-1 monotherapy as first-line treatment in patients with advanced biliary tract cancer: a multicenter phase II study. Cancer Chemother Pharmacol 62: 849-55

[6] Furuse J, Okusaka T, Mlyazaki M, Tainai H, Nimura Y (2009) A randomized study of 
gemcitabine/cisplatin versus single-agent gemcitabine in patients with biliary tract cancer.

Proc Am Soc Clin Oncol 27: abstract no: 4579

[7] Gores GJ (2003) Cholangiocarcinoma: current concepts and insights. Hepatology

37: $961-9$

[8] Jarnagin WR, Ruo L, Little SA, Klimstra D, D'Angelica M, DeMatteo RP, Wagman R, Blumgart LH, Fong Y (2003) Patterns of initial disease recurrence after resection of gallbladder carcinoma and hilar cholangiocarcinoma: implications for adjuvant therapeutic strategies. Cancer 98: 1689-700

[9] Kiba T, Nishimura T, Matsumoto S, Hatano E, Mori A, Yasumi S, Doi R, Ikai I, Kitano T, Nishimura T, Yoshikawa K, Ishiguro H, Yanagihara K, Doi E, Teramukai S, Fukushima M (2006) Single-agent gemcitabine for biliary tract cancers. Study outcomes and systematic review of the literature. Oncology 70: 358-65.

[10] Knox JJ, Hedley D, Oza A, Feld R, Siu LL, Chen E, Nematollahi M,Pond GR, Zhang J, Moore MJ (2005) Combining gemcitabine and capecitabine in patients with advanced biliary cancer: a phase II trial. J Clin Oncol 23: 2332-8

[11] Koeberle D, Saletti P, Borner M, Gerber D, Dietrich D, Caspar CB, Mingrone W, Beretta K, Strasser F, Ruhstaller T, Mora O, Herrmann R (2008) Patient-reported outcomes of patients with advanced biliary tract cancers receiving gemcitabine plus capecitabine: a 
multicenter, phase II trial of the Swiss Group for Clinical Cancer Research. J Clin Oncol 26:

$3702-8$

[12] Koizumi W, Akiya T, Sato A, Sakuyama T, Sasaki E, Tomidokoro T, Hamada T, Fujimori M, Kikuchi Y, Shimada K, Mine T, Yamaguchi K, Sasaki T, Kurihara M Phase II study of S-1 as first-line treatment for elderly patients over 75 years of age with advanced gastric cancer: the Tokyo Cooperative Oncology Group study. Cancer Chemother Pharmacol 65: 1093-9

[13] Leonard GD, O'Reilly EM (2005) Biliary tract cancers: current concepts and controversies. Expert Opin Pharmacother 6: 211-23

[14] Morizane C, Okusaka T, Furuse J, Ishii H, Ueno H, Ikeda M, Nakachi K, Najima M, Ogura T, Suzuki E (2009) A phase II study of S-1 in gemcitabine-refractory metastatic pancreatic cancer. Cancer Chemother Pharmacol 63: 313-9

[15] Nakamura K, Yamaguchi T, Ishihara T, Sudo K, Kato H, Saisho H (2006) Phase II trial of oral S-1 combined with gemcitabine in metastatic pancreatic cancer. $\mathrm{Br} \mathrm{J}$ Cancer 94: $1575-9$

[16] Oh DY, Cha Y, Choi IS, Yoon SY, Choi IK, Kim JH, Oh SC, Kim CD, Kim JS, Bang YJ, Kim YH A multicenter phase II study of gemcitabine and S-1 combination chemotherapy in patients with unresectable pancreatic cancer. Cancer Chemother Pharmacol 65: 527-36 
[17] Okusaka T, Ishii H, Funakoshi A, Yamao K, Ohkawa S, Saito S, Saito H,

Tsuyuguchi T (2006) Phase II study of single-agent gemcitabine in patients with advanced biliary tract cancer. Cancer Chemother Pharmacol 57: 647-53

[18] Penz M, Kornek GV, Raderer M, Ulrich-Pur H, Fiebiger W, Lenauer A, Depisch D, Krauss G, Schneeweiss B, Scheithauer W (2001) Phase II trial of two-weekly gemcitabine in patients with advanced biliary tract cancer. Ann Oncol 12: 183-6

[19] Sakuramoto S, Sasako M, Yamaguchi T, Kinoshita T, Fujii M, Nashimoto A, Furukawa H, Nakajima T, Ohashi Y, Imamura H, Higashino M, Yamamura Y, Kurita A, Arai K (2007) Adjuvant chemotherapy for gastric cancer with S-1, an oral fluoropyrimidine. N Engl J Med 357: 1810-20

[20] Sasaki T, Isayama H, Nakai Y, Ito Y, Kogure H, Togawa O, Toda N, Yasuda I, Hasebe O, Maetani I, Sasahira N, Hirano K, Tsujino T, Tada M, Omata M (2010) Multicenter, phase II study of gemcitabine and S-1 combination chemotherapy in patients with advanced biliary tract cancer. Cancer Chemother Pharmacol. 65: 1101-7

[21] Therasse P, Arbuck SG, Eisenhauer EA, Wanders J, Kaplan RS, Rubinstein L, Verweij J, Van Glabbeke M, van Oosterom AT, Christian MC, Gwyther SG (2000) New guidelines to evaluate the response to treatment in solid tumors. European Organization for Research and Treatment of Cancer, National Cancer Institute of the United States, National 
Cancer Institute of Canada. J Natl Cancer Inst 92: 205-16

[22] Trotti A, Colevas AD, Setser A, Rusch V, Jaques D, Budach V, Langer C, Murphy B, Cumberlin R, Coleman CN, Rubin P (2003) CTCAE v3.0: development of a comprehensive grading system for the adverse effects of cancer treatment. Semin Radiat Oncol 13: 176-81 [23] Tsavaris N, Kosmas C, Gouveris P, Gennatas K, Polyzos A, Mouratidou D, Tsipras H, Margaris H, Papastratis G, Tzima E, Papadoniou N, Karatzas G, Papalambros E (2004) Weekly gemcitabine for the treatment of biliary tract and gallbladder cancer. Invest New Drugs 22: 193-8

[24] Ueno H, Okusaka T, Ikeda M, Takezako Y, Morizane C (2004) Phase II study of S-1 in patients with advanced biliary tract cancer. $\mathrm{Br} \mathrm{J}$ Cancer 91: 1769-74

[25] Valle JW, Wasan H, Johnson P, Jones E, Dixon L, Swindell R, Baka S, Maraveyas A, Corrie P, Falk S, Gollins S, Lofts F, Evans L, Meyer T, Anthoney A, Iveson T, Highley M, Osborne R, Bridgewater J (2009) Gemcitabine alone or in combination with cisplatin in patients with advanced or metastatic cholangiocarcinomas or other biliary tract tumours: a multicentre randomised phase II study - The UK ABC-01 Study. Br J Cancer 101: 621-7 [26] Valle J, Wasan H, Palmer DH, Cunningham D, Anthoney A, Maraveyas A, Madhusudan S, Iveson T, Hughes S, Pereira SP, Roughton M, Bridgewater J; ABC-02 Trial Investigators (2010). Cisplatin plus gemcitabine versus gemcitabine for biliary tract 
cancer. N Engl J Med 362:1273-81.

[27] von Delius S, Lersch C, Schulte-Frohlinde E, Mayr M, Schmid RM, Eckel F (2005)

Phase II trial of weekly 24-hour infusion of gemcitabine in patients with advanced gallbladder and biliary tract carcinoma. BMC Cancer 5: 61

[28] Yamauchi J, Kanai M, Matsumoto S, Nishimura T, Yazumi S, Kami K, Kawaguchi Y, Yasuda H, Kitano T, Misawa A, Ishiguro H, Yoshikawa K, Yanagihara K, Fukushima M, Doi R, Chiba T (2008) Clinical outcome of gemcitabine/S-1 combination therapy for advanced pancreatic cancer. Pancreas $36: 327-8$

[29] Yanagihara K, Yoshimura K, Niimi M, Yasuda H, Sasaki T, Nishimura T, Ishiguro H, Matsumoto S, Kitano T, Kanai M, Misawa A, Tada H, Teramukai S, Mio T, Fukushima M (2010) Phase II study of S-1 and docetaxel for previously treated patients with locally advanced or metastatic non-small cell lung cancer. Cancer Chemother Pharmacol. doi: $10.1007 / \mathrm{s} 00280-009-1239-7$

[30] Yoshizawa J, Takizawa A, Takeuchi O, Hiraku O, Sasaki K, Morimoto Y, Atsuda K, Inoue G, Suzuki Y, Asanuma F, Yamada Y (2009). Experimental study of combination therapy with S-1 against pancreatic cancer. Cancer Chemother Pharmacol. 64:1211-9. 
Table 1. Characteristics of patients with advanced biliary tract cancer $(n=25)$

\begin{tabular}{lc}
\hline Sex & \\
Male & $18(72.0 \%)$ \\
Female & $7(28.0 \%)$ \\
\hline Median age (years) & 63 (range $32-78)$ \\
\hline Primary lesion & $5(20.0 \%)$ \\
Intrahepatic & $11(44.0 \%)$ \\
Extrahepatic & $8(32.0 \%)$ \\
Gallbladder & $1(4.0 \%)$ \\
Ampulla of Vater & \\
Disease status & $21(84.0 \%)$ \\
Unresectable & $4(16.0 \%)$ \\
Recurrent &
\end{tabular}

Target lesion

Primary

Liver

Lymph node

Peritoneum

Local recurrence

Lung

None 2

\begin{tabular}{lc} 
Median no. treatment cycles & 7 (range 1-20) \\
Median CEA $(\mathrm{ng} / \mathrm{mL})$ & 4.5 (range 0.3-468) \\
Median CA19-9 $(\mathrm{U} / \mathrm{mL})$ & 167 (range 1-6373) \\
\hline
\end{tabular}

CEA, carcinoembryonic antigen; CA 19-9, carbohydrate antigen.

* One patient had a history of adjuvant chemotherapy using gemcitabine. 
Table 2. Hematologic adverse events among patients with advanced biliary tract cancer treated with gemcitabine/S-1 combination chemotherapy $(n=25)$

\begin{tabular}{lccccc}
\hline & Grade 1 & Grade 2 & Grade 3 & Grade 4 & $\begin{array}{c}\text { Incidence of } \\
\text { grade 3-4 } \\
\text { events (\%) }\end{array}$ \\
\hline Neutropenia & 0 & 5 & 12 & 2 & 56 \\
Leukopenia & 1 & 9 & 6 & 0 & 24 \\
\hline Anemia & 5 & 7 & 1 & 1 & 8 \\
Thrombocytopenia & 1 & 4 & 1 & 0 & 4 \\
\hline Febrile neutropenia & - & - & 0 & 0 & 0 \\
\hline
\end{tabular}


Table 3. Non-hematological adverse events among patients with advanced biliary tract cancer treated with gemcitabine/S-1 combination chemotherapy $(n=25)$

\begin{tabular}{|c|c|c|c|c|c|c|}
\hline & Grade 1 & Grade 2 & Grade 3 & Grade 4 & $\begin{array}{c}\text { Incidence } \\
\text { of grade } \\
\text { 3-4 events } \\
(\%)\end{array}$ & $\begin{array}{c}\text { Incidence } \\
\text { of grade } \\
1-4 \text { events } \\
\text { (\%) }\end{array}$ \\
\hline Fatigue & 8 & 3 & 2 & 0 & 8 & 52 \\
\hline Anorexia & 3 & 2 & 2 & 0 & 8 & 28 \\
\hline Diarrhea & 1 & 4 & 1 & 0 & 4 & 24 \\
\hline Constipation & 1 & 6 & 0 & 0 & 0 & 28 \\
\hline Rash & 9 & 3 & 0 & 0 & 0 & 48 \\
\hline Fever & 8 & 3 & 0 & 0 & 0 & 44 \\
\hline Hand-foot rash & 7 & 3 & 0 & - & 0 & 40 \\
\hline Infection-other & 8 & 2 & 0 & 0 & 0 & 40 \\
\hline Nausea & 3 & 2 & 0 & 0 & 0 & 20 \\
\hline Stomatitis & 5 & 1 & 0 & 0 & 0 & 24 \\
\hline Allergic reaction & 4 & 1 & 0 & 0 & 0 & 20 \\
\hline Hyperpigmentation & 8 & 0 & - & - & 0 & 32 \\
\hline Alopecia & 3 & 0 & - & - & 0 & 12 \\
\hline $\begin{array}{l}\text { Injection site } \\
\text { reaction }\end{array}$ & 2 & 0 & 0 & - & 0 & 8 \\
\hline Vomiting & 1 & 0 & 0 & 0 & 0 & 4 \\
\hline Hyperbilirubinemia & 3 & 1 & 4 & 0 & 16 & 32 \\
\hline AST & 11 & 5 & 0 & 0 & 0 & 64 \\
\hline ALT & 8 & 4 & 2 & 0 & 8 & 56 \\
\hline Creatinine & 3 & 0 & 0 & 0 & 0 & 12 \\
\hline
\end{tabular}

AST, aspartate aminotransferase; ALT, alanine aminotransferase. 
Table 4. Results of clinical trials of gemcitabine and oral fluoropyrimidine combination chemotherapy for the treatment of advanced biliary tract cancer

\begin{tabular}{|c|c|c|c|c|c|}
\hline & $\begin{array}{l}\text { Present } \\
\text { study }\end{array}$ & $\begin{array}{c}\text { Sasaki et al. } \\
\text { [19] }\end{array}$ & $\begin{array}{l}\text { Knox et al. } \\
{[10]}\end{array}$ & Cho et al. [2] & $\begin{array}{c}\text { Koeberle et al. } \\
\text { [11] }\end{array}$ \\
\hline Oral fluoropyrimidine & S-1 & S-1 & Capecitabine & Capecitabine & Capecitabine \\
\hline MST (months) & 12.7 & 11.6 & 14 & 14 & 13.2 \\
\hline 1-year survival rate $(\%)$ & 52 & 44 & 49 & 58 & $\mathrm{~N} / \mathrm{A}$ \\
\hline $\begin{array}{l}\text { Prevalence of gall } \\
\text { bladder cancer (\%) }\end{array}$ & 32 & 40 & 49 & 16 & 18 \\
\hline $\begin{array}{l}\text { Incidence of grade 3-4 } \\
\text { neutropenia (\%) }\end{array}$ & 56 & 34 & 34 & 11 & $11^{\mathrm{a}}$ \\
\hline $\begin{array}{l}\text { Incidence of grade 3-4 } \\
\text { anorexia }(\%)\end{array}$ & 8 & 3 & $\mathrm{~N} / \mathrm{A}$ & 2 & 7 \\
\hline $\begin{array}{l}\text { Incidence of grade 3-4 } \\
\text { fatigue (\%) }\end{array}$ & 8 & $\mathrm{~N} / \mathrm{A}$ & 4 & 0 & 11 \\
\hline Sample size & 25 & 35 & 45 & 44 & 44 \\
\hline
\end{tabular}

MST, median survival time; N/A, not available. ${ }^{\mathrm{a}}$ These subjects had leukopenia. 